\title{
Mass spectrometric behaviors and molecular mechanisms of Amadori compounds between acute lung injury and diabetes based on network pharmacology
}

\author{
Yunpeng Bai ${ }^{1,2 \#} \wedge$, Jiaxin $\mathrm{Li}^{3 \#}$, Guangwen Wang ${ }^{2,4 \#}$, Guowu Liang ${ }^{2}$, Yanhong $\mathrm{He}^{2}$, Linhui $\mathrm{Hu}^{1,2}$, \\ Chunbo Chen ${ }^{1,2,3,5,6,7} \wedge$
}

${ }^{1}$ Department of Critical Care Medicine, Maoming People's Hospital, Maoming, China; ${ }^{2}$ Center of Scientific Research, Maoming People's Hospital, Maoming, China; 'Department of Intensive Care Unit of Cardiac Surgery, Guangdong Cardiovascular Institute, Guangdong Provincial People's Hospital, Guangdong Academy of Medical Sciences, Guangzhou, China; ${ }^{4}$ Department of Neurology, Maoming People's Hospital, Maoming, China; ${ }^{5}$ Department of Emergency, Maoming People's Hospital, Maoming, China; ${ }^{6}$ Department of Critical Care Medicine, Guangdong Provincial People's Hospital, Guangdong Academy of Medical Sciences, Guangzhou, China; ${ }^{7}$ The Second School of Clinical Medicine, Southern Medical University, Guangzhou, China

Contributions: (I) Conception and design: C Chen, Y Bai, J Li, G Wang; (II) Administrative support: None; (III) Provision of study materials or patients: None; (IV) Collection and assembly of data: G Liang; (V) Data analysis and interpretation: Y Bai, G Wang, Y He, L Hu; (VI) Manuscript writing: All authors; (VII) Final approval of manuscript: All authors.

"These authors contributed equally to this work.

Correspondence to: Chunbo Chen. Department of Critical Care Medicine, Maoming People’s Hospital, Maoming, China. Email: gghccm@163.com.

Background: With its complex pathogenesis and high mortality, acute lung injury (ALI) is closely associated with a poor prognosis in critically ill patients. The present study used network pharmacology to investigate the mass spectrometry (MS) behaviors and molecular mechanisms of Amadori compounds acting on ALI and diabetes.

Methods: Two typical Amadori compounds (Fru-Trp and Glc( 1,4)-Fru-Trp) were used to study the fragmentation mechanisms by tandem MS in negative and positive-ion modes. The potential targets of Amadori compounds on ALI were screened from a public database. R package was used for the Gene Ontology (GO) and Kyoto Encyclopedia of Genes and Genomes (KEGG) pathway analyses, and the protein-protein interactions (PPIs) of the targets were evaluated by Search Tool for the Retrieval of Interacting Genes (STRING). Finally, molecular docking was implemented to analyze the binding energies and action modes of the target compounds through the online tool CB-Dock.

Results: In relation the common precursor ions of the Amadori compounds, the sodium adducting cations provided the most abundant fragmentation information in c for analyzing their chemical structures. 103 and 109 intersecting targets of glucose-Amadori and maltose-Amadori, respectively, were separately identified in the ALI database, and significant overlaps between the GO terms and KEGG pathways were noted. Three shared hub targets (i.e., vascular endothelial growth factor A, caspase-3, and proto-oncogene tyrosine-protein kinase) were selected from the 2 PPI networks by STRING. The molecular docking results showed that the Amadori compounds had good binding potential to the hub target proteins, and that Amadori compounds had lower binding energies and more stable conformations than their corresponding carbohydrates.

Conclusions: As the endogenous compounds in diabetes, Amadori compounds may act on and activate a wide range of protein receptors, which may also produce bi-directional regulatory effects that influence ALI progression. Thus, the risk factors of diabetes in the progression of ALI should be carefully assessed, and the molecular mechanisms of Amadori compounds in animal models for ALI should be further verified.

^ ORCID: Yunpeng Bai, 0000-0001-7862-1817; Chunbo Chen, 0000-0001-5662-497X. 
Koywords: Acute lung injury (ALI); diabetes; Amadori compounds; mass spectrometry; network pharmacology

Submitted Oct 15, 2021. Accepted for publication Nov 25, 2021.

doi: 10.21037/apm-21-3298

View this article at: https://dx.doi.org/10.21037/apm-21-3298

\section{Introduction}

Acute lung injury (ALI) refers to a clinical syndrome distinguished by uncontrolled progressive lung inflammation with gas-exchange dysfunction and alveolar-capillary barrier disruption. Patients suffering from ALI may progress to the severe stage of acute respiratory distress syndrome (ARDS). ALI and ARDS can lead to acute respiratory failure, and have a mortality rate as high as 40-60\%; and various pathologies, such as hypoxemia, respiratory distress, microbial infection, and pulmonary edema, may lead to these diseases $(1,2)$. Several molecular mechanisms, including inflammatory responses, oxidative stress, the proliferation, migration, and apoptosis of vascular endothelial cells (ECs), and immune system processes, are related to the pathogenesis and progression of ALI (3). Characteristics of ALI include excessive neutrophil and macrophage infiltration into lung tissues, the release of proinflammatory cytokines, and lung endothelial and epithelial injuries (4). Numerous studies have sought to further understand the pathophysiology of ALI; however, knowledge of specific targeted drugs to treat ALI remains lacking (5).

Because the development of ALI is related to short- and long-term morbidity, prolonged hospitalization, and high medical expenses, it is very important to determine the risk factors of the disease (6). Diabetes, a global health priority, is a metabolic disease defined by chronic hyperglycemia, which is often characterized by dyslipidemia, insulin resistance, and insulin dependence. It is predicted that the incidence of diabetes will rise sharply by 2025 (7). However, the effect of diabetes on the risk and outcomes of ALI in critically ill patients remains unclear. Thus, the relationship between diabetes and mortality in critically ill patients remains controversial. For example, some studies suggest that existing diabetes may reduce the risk of ARDS in critically ill adults; however, others suggest that diabetes is related to an increased risk of ARDS in post-operative patients (8-10). Still other studies have shown that diabetes is not related to ARDS in the intensive care unit population (11-13). In addition, hyperglycemia and the non-glycemic sequelae of diabetes may play a role in the development of
ALI/ARDS (14). The common treatments for diabetes, such as insulin and peroxisome proliferators-activated receptor agonists, may alter the effect of diabetes on ALI/ARDS (15). Given these inconsistencies, the mechanisms underlying the association between diabetes and ALI/ARDS must be further studied and explored at the pharmacological level.

The Maillard reaction refers to chemical reaction between carbonyl compounds (e.g., aldehydes, ketones, and reducing sugars) and amino compounds (e.g., amines, amino acids, polypeptides, and proteins). Amadori compounds (N-substituted 1-amino-1-deoxyketoses) are the key intermediates formed by the Amadori rearrangement in the initial step of Maillard reaction, which can be considered as the spontaneous process in vivo (16). Advanced glycation end products in the final step of Maillard reaction play important roles in the long-term sequelae of diabetes; however, the concentrations of Amadori compounds are increased in diabetic patients due to hyperglycemia and may be also involved in the secondary complications of diabetes, such as microangiopathy $(17,18)$. Because of the complex signaling pathways of ALI/ARDS, it is worth to explore the molecular mechanisms of the high concentrations of Amadori compounds in detail about their pharmacological or toxicological effects. A single crystal X-ray analysis of certain Amadori compounds illuminated the exact 3-dimensional (3D) structures, such as carbohydrate conformations and connection patterns with amino acids $(19,20)$. With the recent development of soft ionization technology in mass spectrometry (MS), several Amadori compounds have been analyzed by high-performance liquid chromatography (HPLC) combined with tandem MS (MS/ MS) $(21,22)$. Further, the fragmentation mechanism of $[\mathrm{M}+\mathrm{H}]^{+}$in Amadori compounds synthesized from glucose (GLC) and various amino acids was systematically studied by electron spray ionization (ESI)-MS/MS in the positiveion mode (23). We previously analyzed the structure and isomers of Amadori compounds synthesized from maltose and lactose, respectively (24).

Network pharmacology could provide new methods for discovering drugs to treat complex diseases and understand the multiple mechanisms of drug actions (25). Combining 
pharmacology, bioinformatics, and other sciences with systematic network analyses, the construction of 'diseasephenotype-gene-drug' networks could help to explain the mechanisms of multi-component and multi-target drug treatments from the perspectives of gene distribution, molecular function (MF), and signaling pathways. In this study, we conducted a network pharmacological analysis to clarify the molecular target and potential mechanism of the Amadori compounds affecting ALI and diabetes. The mass spectrometric behaviors of typical Amadori compounds were also systemically evaluated to investigate the relevant fragmentation pathways under different MS conditions, including $[\mathrm{M}-\mathrm{H}]^{-},[\mathrm{M}+\mathrm{H}]^{+},[\mathrm{M}+\mathrm{Na}]^{+}$and $[\mathrm{M}+\mathrm{K}]^{+}$. Compared with previous study, our tandem MS results may be helpful in the analysis of the chemical structures of other unknown Amadori analogs from different sources of biological samples. We present the following article in accordance with the MDAR reporting checklist (available at https://dx.doi.org/10.21037/apm-21-3298).

\section{Methods}

\section{Materials}

Glucose (GLC), maltose (MAL), and tryptophan (TRP) were purchased from the Huishi Biochemical Reagent Co. Ltd. (Shanghai, China). HPLC-grade methanol (Thermo Fisher, USA) and pure water were prepared by the Milli-Q system. The reaction temperature was controlled by an SHH W21 4203 electric heating thermostatic water bath boiler (Yuyao Dongfang Electrical Instrument Factory).

\section{Sample preparation}

Approximately $0.5 \mathrm{~g}$ of each carbohydrate and $0.5 \mathrm{~g}$ of TRP were mixed with $60 \mathrm{~mL}$ of methanol in a $100-\mathrm{mL}$ roundbottom flask. Samples of the individual Amadori compounds were prepared by refluxing in methanol at $80{ }^{\circ} \mathrm{C}$ for 3 hours. After the solution was cooled to room temperature, the precipitates (i.e., the unreacted carbohydrates and TRP) were removed by filtration, and the filtrate was then collected and evaporated to dryness. The residues were redissolved with $50 \%$ aqueous methanol, and filtered through a $0.22-\mu \mathrm{m}$ filter for the ESI-MS analysis.

\section{ESI-MS analysis}

Mass spectrometric experiments were carried out on a linear ion trap mass spectrometer (LTQ-XL, Thermo, San Jose, CA, USA) equipped with an electrospray source. Sample solutions were injected by a syringe pump at a flow rate of $10 \mu \mathrm{L} / \mathrm{min}$, and all data were obtained in negative and positive-ion modes. The capillary temperature was set at $250{ }^{\circ} \mathrm{C}$, and high-purity nitrogen $(99.9 \%)$ was used as sheath gas with a flow rate of 40 arbitrary units. In the negative-ion mode, the spray voltage was set to $-3.00 \mathrm{kV}$, the tube lenses were offset to $-250 \mathrm{~V}$, and the capillary voltage was set at $-45 \mathrm{~V}$. In the positive-ion mode, the spray voltage was set to $4.00 \mathrm{kV}$, the tube lenses were offset to $150 \mathrm{~V}$, and the capillary voltage was set at $25 \mathrm{~V}$. Sodium and potassium ions can come from glass containers or impurities introduced during the preparation of Amadori compounds. In the MS/MS experiments, the window for precursor ion selection was $2.0 \mathrm{Th}$. The normalized collision energy was set at $15-30 \%$ and adjusted until the intensity ratio of the precursor peak to the base peak was between 5 and 40 .

\section{Potential targets of the Amadori compounds-ALI regulatory network}

The study was conducted in accordance with the Declaration of Helsinki (as revised in 2013). The 2-dimensional (2D) structures of the Amadori compounds were drawn by ChemDraw software, which included glycine, alanine, serine (SER), threonine, leucine, isoleucine, valine, glutamic acid, aspartic acid, asparaginate, glutamine, proline, histidine, phenylalanine, cysteine, methionine, arginine, lysine, tyrosine (TYR), TRP, GLC, and MAL. To identify the targets of the Amadori compounds, the Swiss TargetPrediction database (http:// www.swisstargetprediction.ch/), a web server, was used to predict the most probable protein targets of small molecules based on the combination of 2D and 3D similarity measures of known ligands $(26,27)$. The spatial data format (SDF) files of the Amadori compounds were imported into the SwissTargetPrediction database for gene symbols of these identified candidate targets. To identify the diseaserelated genes, the ALI-related genes were collected from GeneCards (https://www.genecards.org/). Targets with hit scores $>10.0$ were selected as the ALI-related genes. The UniProt database (http://www.uniprot.org/) was used to compare target information and gene symbol standardization. Subsequently, the regulatory networks of GLC-Amadori-ALI and MAL-Amadori-ALI were generated using the Cytoscape software. 


\section{GO and KEGG enrichment analysis}

The Gene ontology (GO) analysis is a common method for defining genes and their ribonucleic acid or protein products to determine the specific biological characteristics of high-throughput transcriptome or genome data (28). It is mainly used to study biological processes (BPs), cellular composition (CCs), and MFs. The Kyoto Encyclopedia of Genes and Genomes (KEGG) is a collection of databases referring to genomes, diseases, biological pathways, drugs, and chemical materials (29). To investigate the biological effects of the Amadori compounds, GO and KEGG pathway enrichment analyses were conducted and calculated by R packages, including "clusterProfiler", "encichplot", and "ggplot2". The enriched GO terms and pathways with a corrected $\mathrm{P}$ value $<0.05$ were chosen for further analysis.

\section{PPI network and topological analysis}

PPI is the basis of most BPs in living cells and is essential for understanding cell physiology under normal and disease conditions. PPI network mappings originated from the Amadori compounds and ALI targets were performed using the online Search Tool for the Retrieval of Interacting Genes (STRING) (https://string-db.org/) with a confidence score $\geq 0.4$ (30).

\section{Molecular docking}

To investigate the relationship between the target proteins and ligands at the molecular level, molecular docking experiments were conducted to evaluate the intensity and mode of interaction between typical Amadori compounds and the targets. The docking simulation was carried out by CB-Dock (http://cao.labshare.cn/cb-dock/), which can automatically recognize the binding sites of a given protein, calculate the center position, customize the size of the docking box, and use the popular docking program (AutoDock Vina) to dock with the query ligands (31). The $3 \mathrm{D}$ crystal structures of the target proteins were downloaded from the protein data bank (http://www.rcsb. org), and the Amadori compounds and corresponding carbohydrates were optimized by Gauss software. Next, the protein and the Amadori compounds/carbohydrates were uploaded to CB-Dock for docking. The docking scores were used to compare the theoretical binding affinities of the Amadori compounds and carbohydrate molecules to the key targets.

\section{Statistical analysis}

Statistical analysis was performed using Student's $t$-test by SPSS (version 19.0, Chicago, IL, USA) if applicable. Values of $\mathrm{P}<0.05$ were considered to the statistically significant.

\section{Results}

\section{MS behaviors of the Amadori compounds}

The fragmented ions of the Amadori compounds were labeled according to the nomenclature proposed by Han et al. (32). Ions retaining the charge at the non-reducing terminus were termed A (cross-ring cleavages), B, and C (glycoside cleavages), and ions retaining the charge at the reducing terminus were termed $\mathrm{X}$ (cross-ring cleavages), $\mathrm{Y}$, and $\mathrm{Z}$ (glycoside cleavages). Cross-ring cleavage ions were also designated with superscript numbers to indicate that the 2 bonds were cleaved. The fragmentation patterns of the Amadori compounds, Fru-Trp (GLC-TRP) and Glc $(\alpha 1,4)$-Fru-Trp (MAL-TRP) in the negative-ion mode and positive-ion mode by LTQ-MS/MS are shown in Figures 1,2, respectively. Figure $1 A$ shows the MS/MS spectrum of the $\mathrm{m} / \mathrm{z} 365.0$ ion $\left([\mathrm{M}-\mathrm{H}]^{-}\right)$of GLC-TRP in the negative-ion mode. There are 3 main fragment ions at $m / z 317.0\left({ }^{1,2} \mathrm{X}_{0} \rho^{2,3} \mathrm{X}_{0} \rho^{3,4} \mathrm{X}_{0}{ }^{0,4} \mathrm{X}_{0}-\mathrm{H}_{2} \mathrm{O}\right), 303.0\left({ }^{0,3} \mathrm{X}_{0}\right)$, and $275.0\left({ }^{0,2} \mathrm{X}_{0}\right)$, which can be mainly assigned to $\mathrm{X}$ ions due to the negative charge localization of the carboxyl group under low collision energy conditions. To understand the effects of various cationization conditions on the fragmentation of adduct ions, the MS/MS spectra of GLC-TRP with $\mathrm{H}^{+}$, $\mathrm{Na}^{+}$, and $\mathrm{K}^{+}$were subsequently recorded by LTQ-MS/MS. Figure $1 B$ shows the MS/MS spectrum of the $m / z 367.0$ ion $\left([\mathrm{M}+\mathrm{H}]^{+}\right)$of GLC-TRP in the positive-ion mode, which contains the 4 main fragment ions at $m / z 349.0([\mathrm{M}+\mathrm{H}-$ $\left.\left.\mathrm{H}_{2} \mathrm{O}\right]^{+}\right), 331.0\left(\left[\mathrm{M}+\mathrm{H}-2 \mathrm{H}_{2} \mathrm{O}\right]^{+}\right), 271.0\left({ }^{0,3} \mathrm{X}_{0}-2 \mathrm{H}_{2} \mathrm{O}\right)$, and $\left.229.0{ }^{0,1} \mathrm{X}_{0}-\mathrm{H}_{2} \mathrm{O}\right)$. The assignment of fragmented ions from the precursor ion $[\mathrm{M}+\mathrm{Na}]^{+}$at $m / z 389.0$ of GLC-TRP was as follows (see Figure 1C): $\mathrm{m} / \mathrm{z} 371.0\left(\left[\mathrm{M}+\mathrm{Na}-\mathrm{H}_{2} \mathrm{O}\right]^{+}\right), 353.0$ $\left(\left[\mathrm{M}+\mathrm{Na}-2 \mathrm{H}_{2} \mathrm{O}\right]^{+}\right), 345.0\left(\left[\mathrm{M}+\mathrm{Na}-\mathrm{CO}_{2}\right]^{+}\right), 327.0\left({ }^{0,3} \mathrm{X}_{0}\right)$, $309.0\left({ }^{0,3} \mathrm{X}_{0}-13 \mathrm{H}_{2} \mathrm{O}\right), 269.0\left({ }^{0,1} \mathrm{X}_{0}\right)$, and $227.0\left(\mathrm{Z}_{0}\right)$. Figure $1 D$ shows the MS/MS spectrum of the $m / z 405.0$ ion $\left([\mathrm{M}+\mathrm{K}]^{+}\right)$ of GLC-TRP in the positive-ion mode, which contains 2 main fragment ions at $m / z 387.0\left(\left[\mathrm{M}+\mathrm{K}-\mathrm{H}_{2} \mathrm{O}\right]^{+}\right)$and 285.0 $\left({ }^{0,1} \mathrm{X}_{0}\right)$.

Because of the disaccharide structure of MAL, the fragmentation pathways of MAL-TRP are more complex than those of GLC-TRP. Figure $2 A$ shows the MS/MS spectrum of the $\mathrm{m} / \mathrm{z} 527.0$ ion $\left([\mathrm{M}-\mathrm{H}]^{-}\right)$of MAL-TRP in 

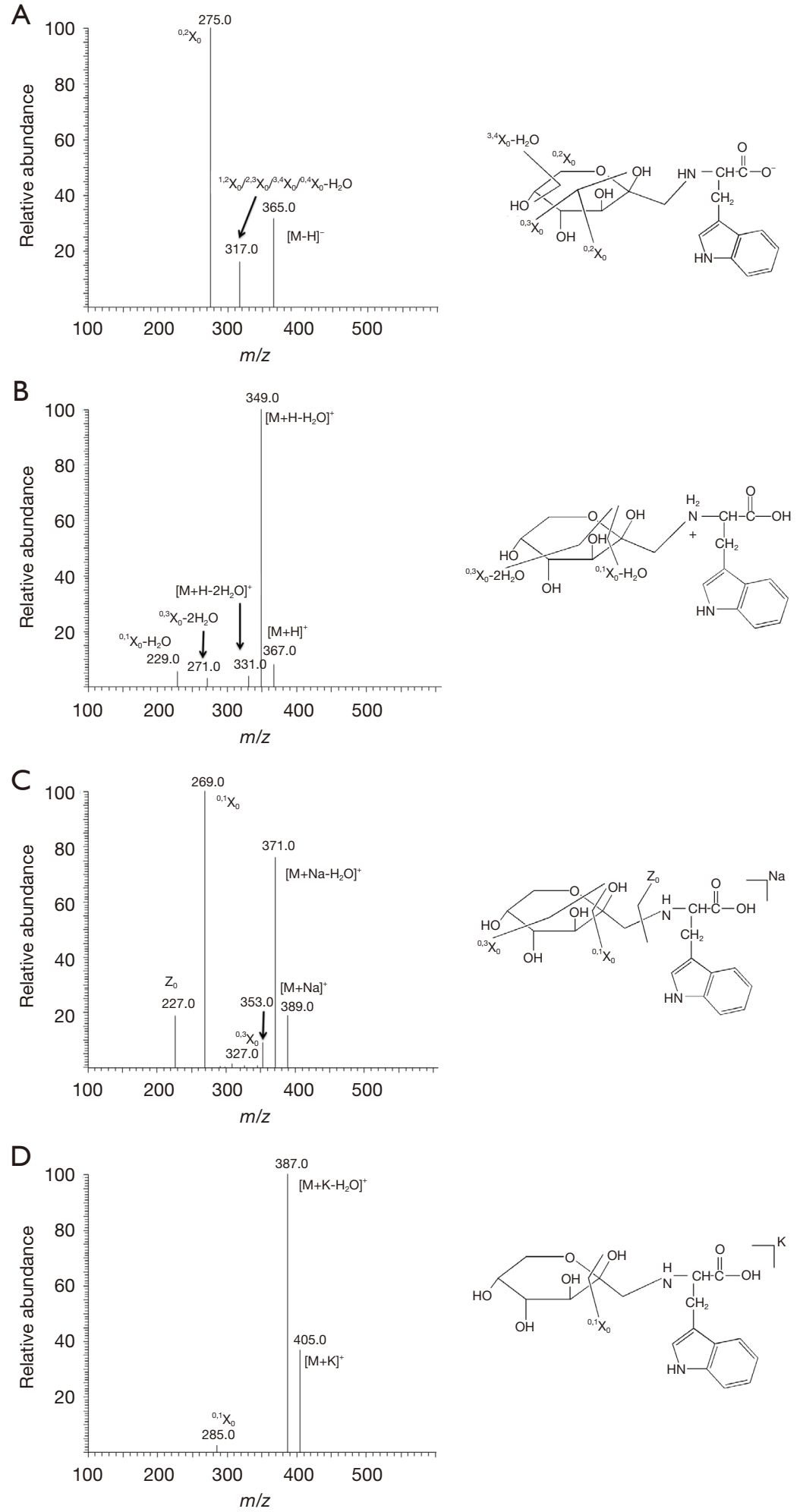

Figure 1 Fragmentation spectrum and pathways of the Amadori compound, Glucose-Tryptophan. (A) tandem mass spectrometry of [M-H] ions and the fragmented mechanisms; (B) tandem mass spectrometry of the $[\mathrm{M}+\mathrm{H}]^{+}$ions and the fragmented mechanisms; $(\mathrm{C})$ tandem mass spectrometry of the $[\mathrm{M}+\mathrm{Na}]^{+}$ions and the fragmented mechanisms; (D) tandem mass spectrometry of the $[\mathrm{M}+\mathrm{K}]^{+}$ions and the fragmented mechanisms. 

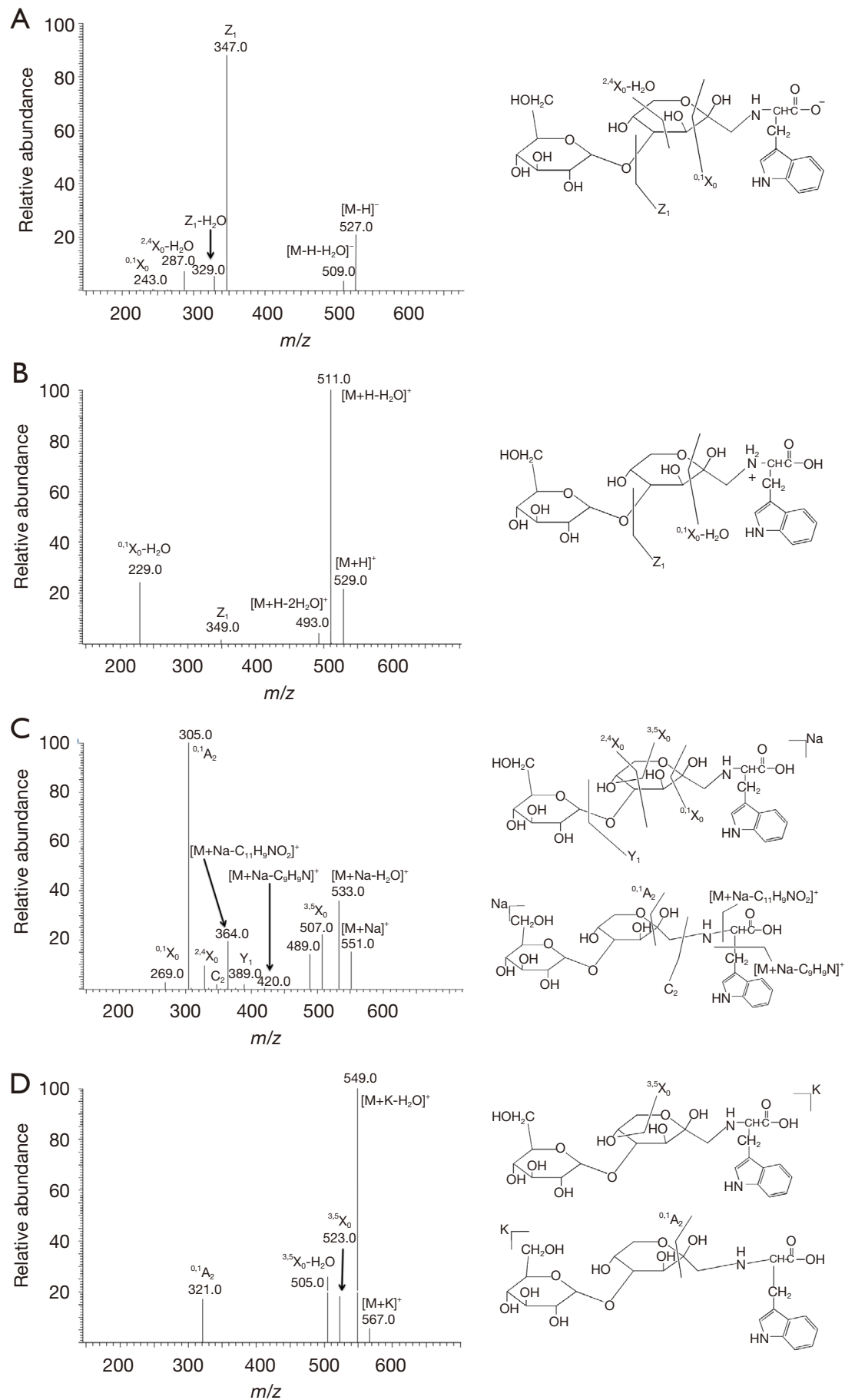

Figure 2 Fragmentation spectrum and pathways of the Amadori compound, Maltose-Tryptophan. (A) tandem mass spectrometry of the [M$\mathrm{H}]^{-}$ions and the fragmented mechanisms; (B) tandem mass spectrometry of $[\mathrm{M}+\mathrm{H}]^{+}$ions and the fragmented mechanisms; $(\mathrm{C})$ tandem mass spectrometry of the $[\mathrm{M}+\mathrm{Na}]^{+}$ions and the fragmented mechanisms; (D) tandem mass spectrometry of the $[\mathrm{M}+\mathrm{K}]^{+}$ions and the fragmented mechanisms. 
the negative-ion mode, which contains 5 main fragment ions at $m / z 509.0\left(\left[\mathrm{M}-\mathrm{H}-\mathrm{H}_{2} \mathrm{O}\right]^{-}\right), 347.0\left(\mathrm{Z}_{1}\right), 329.0\left(\mathrm{Z}_{1}-\right.$ $\left.\mathrm{H}_{2} \mathrm{O}\right), 287.0\left({ }^{2,4} \mathrm{X}_{0}-\mathrm{H}_{2} \mathrm{O}\right)$, and $243.0\left({ }^{0,1} \mathrm{X}_{0}\right)$. The assignment of fragmented ions from the precursor ion $[\mathrm{M}+\mathrm{H}]^{+}$at $\mathrm{m} / \mathrm{z}$ 529.0 of MAL-TRP was as follows in the positive-ion mode (see Figure 2B): $m / z 511.0\left(\left[\mathrm{M}+\mathrm{H}-\mathrm{H}_{2} \mathrm{O}\right]^{+}\right), 493.0$ $\left(\left[\mathrm{M}+\mathrm{H}-2 \mathrm{H}_{2} \mathrm{O}\right]^{+}\right), 349.0\left(\mathrm{Z}_{1}\right)$, and $229.0\left({ }^{0,1} \mathrm{X}_{0}-\mathrm{H}_{2} \mathrm{O}\right)$. Due to the delocalization of sodium ions, the fragments of the $m / z$ 551.0 ion $\left([\mathrm{M}+\mathrm{Na}]^{+}\right)$of MAL-TRP can mainly be assigned to $\mathrm{A}$ and $\mathrm{X}$ ions from successive cross-ring cleavages of sugar moieties (see Figure 2C). According to nitrogen rules, the fragment ions at $420.0\left(\left[\mathrm{M}+\mathrm{Na}-\mathrm{C}_{9} \mathrm{H}_{9} \mathrm{~N}\right]^{+}\right)$, $364.0\left(\left[\mathrm{M}+\mathrm{Na}-\mathrm{C}_{11} \mathrm{H}_{9} \mathrm{NO}_{2}\right]^{+}\right), 347.0\left(\mathrm{C}_{2}\right)$, and $305.0\left({ }^{0,1} \mathrm{~A}_{2}\right)$ corresponded to the neutral losses containing the reducing terminus. The mass differences between the precursor ion $(\mathrm{m} / \mathrm{z}, 551.0)$ and the fragment ions of $\mathrm{m} / \mathrm{z} 507.0\left({ }^{3,5} \mathrm{X}_{0}\right), 389.0$ $\left(\mathrm{Y}_{1}\right), 329.0\left({ }^{2,4} \mathrm{X}_{0}\right)$, and $269.0\left({ }^{0,1} \mathrm{X}_{0}\right)$ are $44,162,222$, and 282 Da, indicating cross-ring cleavages and the loss of a hexose sugar. Additionally, the fragment ions at $\mathrm{m} / \mathrm{z} 533.0([\mathrm{M}+\mathrm{Na}-$ $\left.\mathrm{H}_{2} \mathrm{O}^{+}\right)$and $489.0\left({ }^{3,5} \mathrm{X}_{0}-\mathrm{H}_{2} \mathrm{O}\right)$ matched the loss of 1 water molecule from the precursor $[\mathrm{M}+\mathrm{Na}]^{+}$ion and the ${ }^{3,5} \mathrm{X}_{0}$ ion. Similar to sodium cations, the MS/MS spectrum of the $m / z 567.0$ ion $\left([M+K]^{+}\right)$of MAL-TRP in the positive-ion mode contains 4 main fragment ions at $m / z 549.0([M+K-$ $\left.\left.\mathrm{H}_{2} \mathrm{O}\right]^{+}\right), 523.0\left({ }^{3,5} \mathrm{X}_{0}\right), 505.0\left({ }^{3,5} \mathrm{X}_{0}-\mathrm{H}_{2} \mathrm{O}\right)$, and $321.0\left({ }^{0,1} \mathrm{~A}_{2}\right)$ (see Figure 2D).

\section{Target identification and compound-disease regulatory networks}

Drugs can bind to multiple targets, while molecular targets can participate in multiple processes. Thus, it is necessary to identify the target of Amadori compounds to understand the molecular mechanism of these molecules in the ALI process. In this study, the Swiss TargetPrediction database was used to predict the targets of these compounds and identify the top 100 potential human protein targets of each Amadori compound. A total of 1,451 ALI-related targets were obtained through the GeneCard (see https://cdn.amegroups. cn/static/public/apm-21-3298-1.xlsx), and the AmadoriALI regulatory networks contained 103 and 109 intersecting genes of GLC and MAL-Amadori compounds, respectively (see Figure S1). These results indicate that both kinds of Amadori compounds may have extensive effects on ALI.

\section{GO function and KEGG enrichment analyses}

The functions of the target genes were determined by the
GO analysis using $\mathrm{R}$ package. The gene functions were divided into 3 categories (i.e., BP, CC, and MF). The first 10 enrichment results of the GO analysis were visualized as bar graphs. In relation to the GLC-Amadori compounds, BP is mainly involved in the response to lipopolysaccharides, the regulation of blood pressure, and in the response to molecules of bacterial origins, CC is mainly related to the membrane raft, membrane micro-domain, and membrane region, and MF is mainly involved in endopeptidase activity, amide binding, peptide binding, and protein-TYR kinase activity (see Figure $3 A$ ). In relation to the MAL-Amadori compounds, $\mathrm{BP}$ is mainly involved in the regulation of blood pressure, cellular responses to drugs, and responses to alkaloids, CC is mainly related to the membrane raft, membrane micro-domain, and membrane region, and MF is mainly involved in aspects of endopeptidase activity, amide binding, SER hydrolase activity, and peptide binding (see Figure 3B).

The potential pharmacological mechanisms of AmadoriALI were revealed by the KEGG enrichment analysis. According to the results of the KEGG enrichment analysis, the mechanisms of GLC-Amadori in ALI mainly focus on proteoglycans in cancer, the Phosphatidylinositol-3Kinase and Protein Kinase B (PI3K-Akt) signaling pathway, the Ras-associated protein 1 (Rap1) signaling pathway, the neuroactive ligand-receptor interaction, and the calcium signaling pathway (see Figure $4 A$ ). The mechanisms of MAL-Amadori are mainly concentrated in neuroactive ligand-receptor interactions, the Rap1 signaling pathway, and the PI3K-Akt signaling pathway, proteoglycans in cancer, lipid, and atherosclerosis (see Figure 4B). The identified MFs and BPs are closely related to the occurrence and development of ALI. Thus, Amadori compounds appear to be related to ALI through a variety of targets and pathways.

\section{Integration of PPI networks}

Following the prediction of target gene interactions using the STRING database, PPI networks were constructed to identify the most important proteins and biological molecules responsible for the effect of the Amadori compounds associated with ALI. In relation to the GLCAmadori compounds, a total of 103 nodes and 767 edges were modulated by the PPI network (see Figure 5A); the 10 central nodes were identified as vascular endothelial growth factor A (VEGFA), Caspase-3 (CASP3), protooncogene TYR-protein kinase (SRC), epidermal growth 
A

Response to lipopolysaccharide Regulation of blood pressure Response to molecule of bacterial origin

Cellular response to drug Vascular process in circulatory system Neurotransmitter biosynthetic process Collagen metabolic process Collagen catabolic process Neurotransmitter metabolic process Leukocyte migration Membrane raft Membrane microdomain Membrane region Integral component of presynaptic membrane Integral component of synaptic membrane intrinsic Component of presynaptic membrane Intrinsic component of synaptic membrane Presynaptic membrane Integral component of postsynaptic membrane Intrinsic component of postsynaptic membrane Endopeptidase activity Amide binding Peptide binding Protein tyrosine kinase activity

Metallopeptidase activity Serine hydrolase activity Carboxylic acid binding Cysteine-type endopeptidase activity involved in apoptotic process Organic acid binding Transmembrane receptor protein tyrosine kinase activity

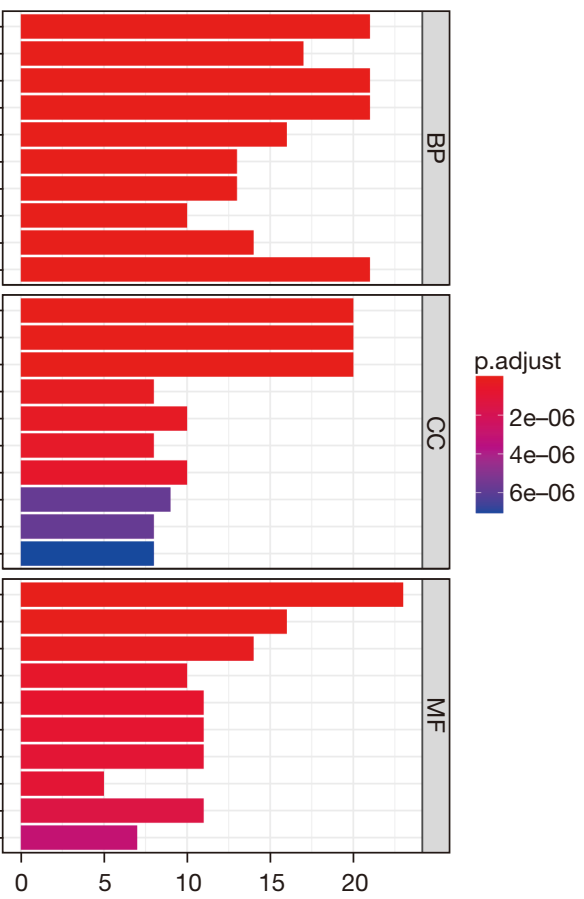

B

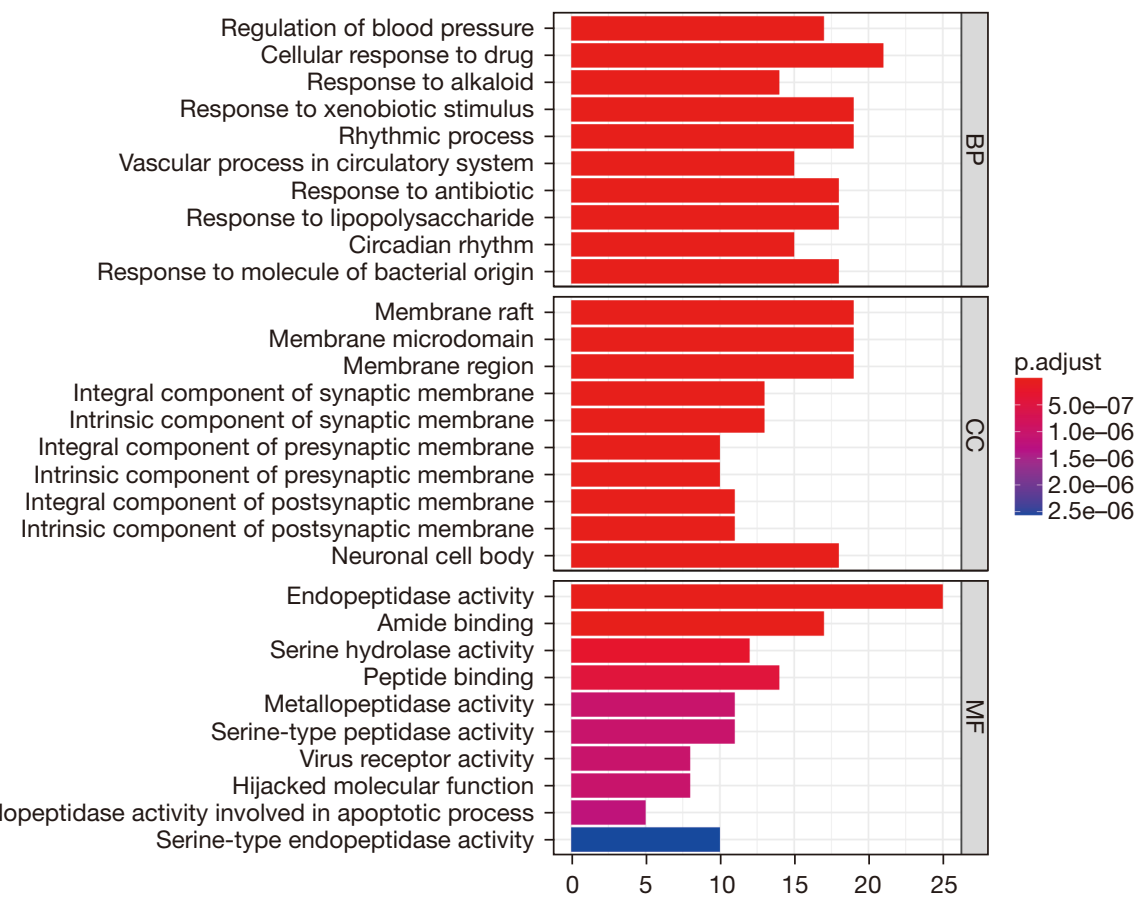

Figure 3 Gene ontology (GO) enrichment analysis of the Amadori targets related to acute lung injury. The horizontal axis of the biological process (BP), cellular composition (CC), and molecular function (MF) column represents the number of genes enriched in each item, and the color represents the enrichment significance based on the corrected P value. (A) Glucose-Amadori compounds; (B) Maltose-Amadori compounds. 

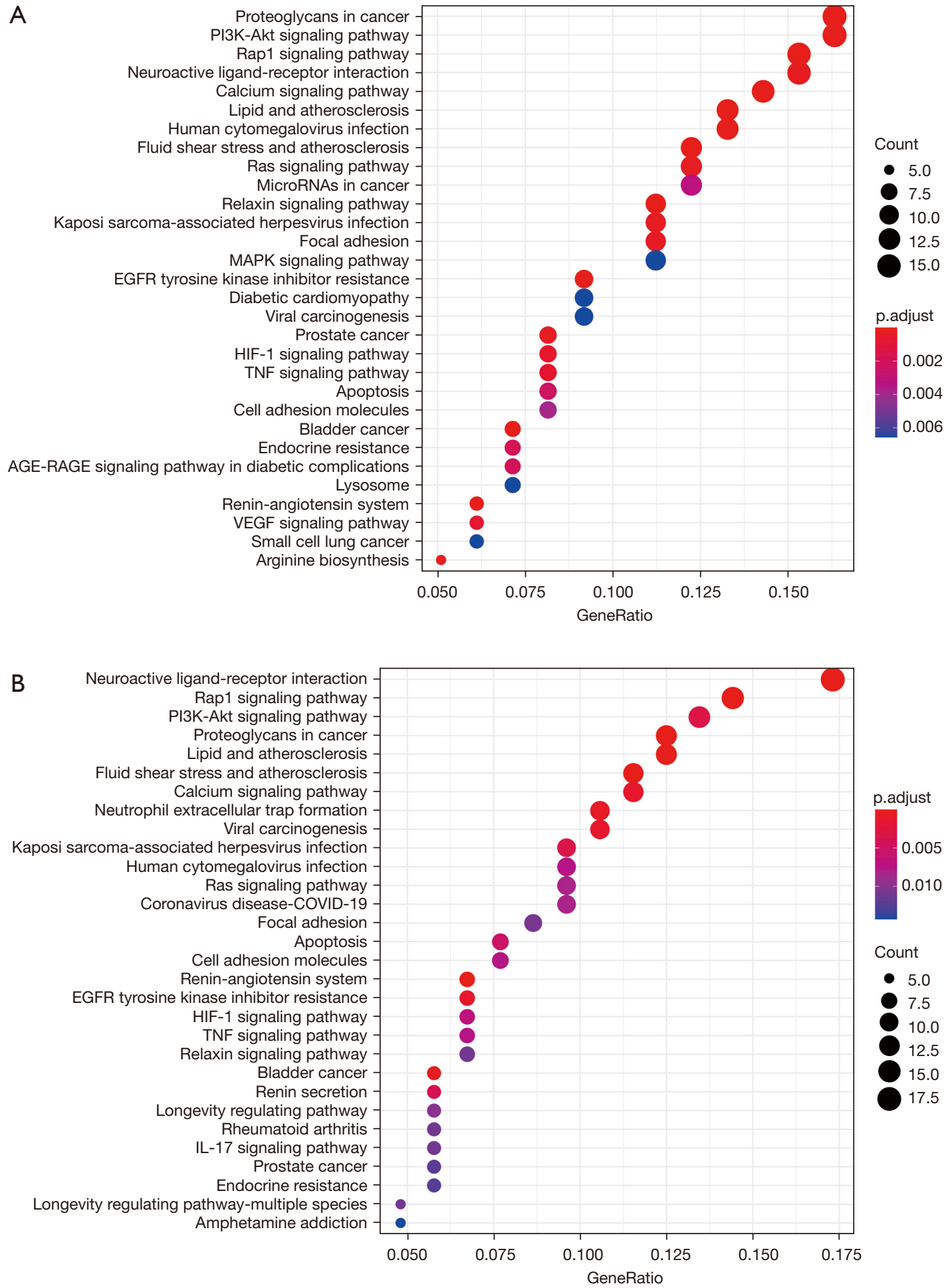

Figure 4 The Kyoto Encyclopedia of Genes and Genomes (KEGG) bubble. The horizontal axis of the KEGG bubble diagram represents the gene proportion enriched in each entry, and the vertical axis shows the enrichment degree according to the corrected $\mathrm{P}$ value. (A) Glucose-Amadori compounds; (B) Maltose-Amadori compounds. 

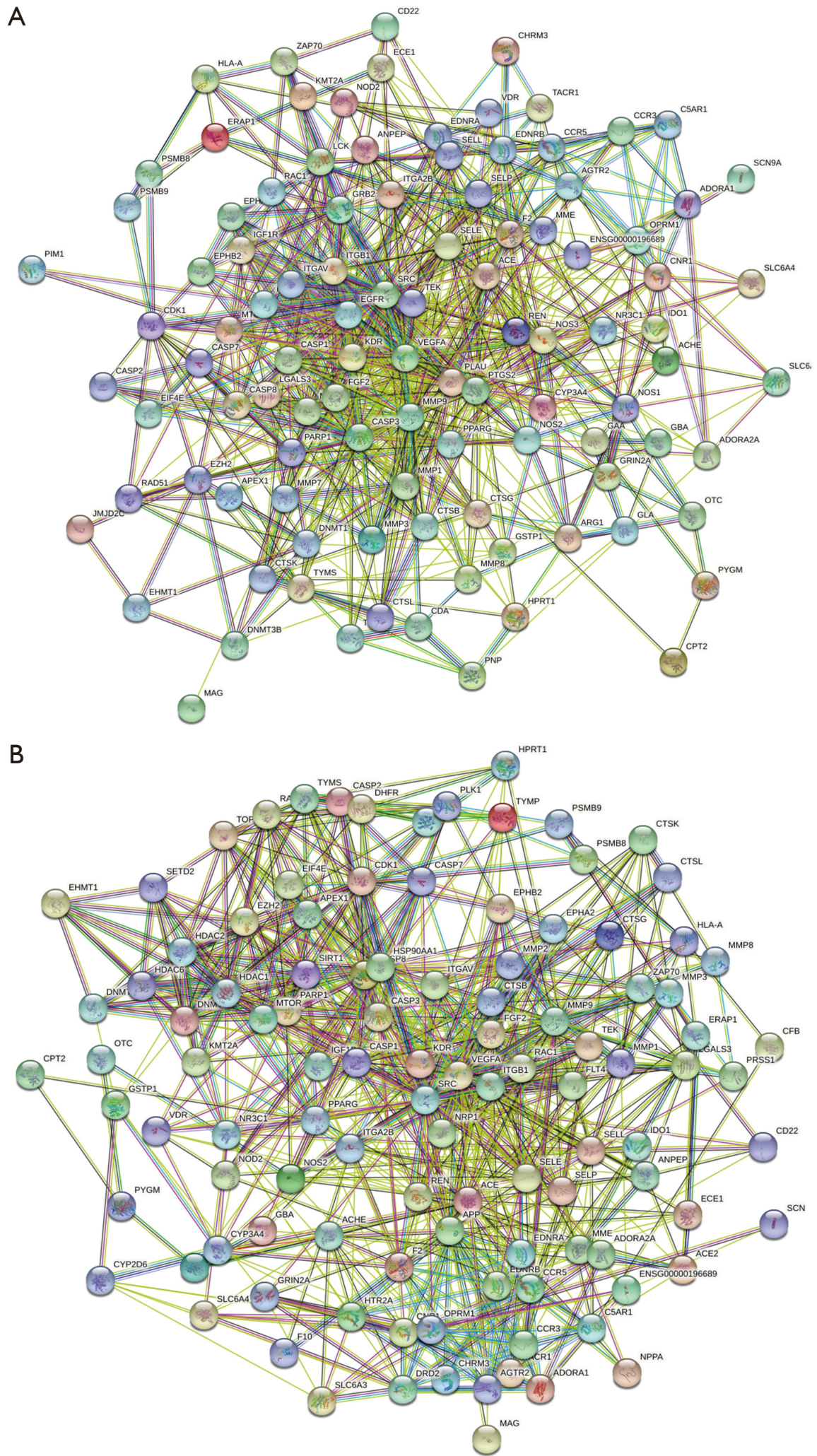

Figure 5 Topological analysis of the protein-protein interactions network. (A) Glucose-Amadori compounds; (B) Maltose-Amadori compounds. 
Table 1 The lowest vina score for each docking

\begin{tabular}{lcccc}
\hline Receptors & Glucose & Glucose-Tryptophan & Maltose & Maltose-Tryptophan \\
\hline Vascular endothelial growth factor A & -4.5 & -5.9 & -4.9 & -6.1 \\
Caspase-3 & -4.5 & -7.2 & -5.8 & -7.7 \\
Proto-oncogene tyrosine-protein kinase Src & -5.6 & -8.2 & -7 & -9.5 \\
\hline
\end{tabular}

factor receptor (EGFR), matrix metalloproteinase-9 (MMP9), fibroblast growth factor 2 (FGF2), prostaglandin $\mathrm{G} / \mathrm{H}$ synthase 2 (PTGS2), $72 \mathrm{kDa}$ type IV collagenase (MMP2), angiotensin-converting enzyme (ACE), and vascular endothelial growth factor receptor 2 (KDR). Similarly, the PPI network of the MAL-Amadori compounds included 109 nodes and 794 edges (see Figure $5 \mathrm{~B}$ ); the top $10 \mathrm{key}$ genes were identified as VEGFA, CASP3, SRC, Heat shock protein HSP 90-alpha (HSP90AA1), MMP9, Amyloid-beta precursor protein (APP), FGF2, MMP2, ACE, and KDR. The hub genes common to these 2 networks (i.e., VEGFA, CASP3, and SRC) were selected for further molecular docking studies to compare the effects of the Amadori compounds related to ALI after Maillard reactions.

\section{Comparison of hub targets by molecular docking}

The Amadori compounds of GLC-TRP and MAL-TRP were selected as molecular docking ligands to compare the effects of GLC and MAL associated with ALI. The optimized structures of the Amadori compounds were separately uploaded to CB-Dock for docking analysis with VEGFA, CASP3, and SRC as targets. Vina scores $<0$ indicated that the targeted proteins and ligands can bind spontaneously, and lower docking scores reflected more stable conformations. The docking scores of the first 5 conformations in each docking result are shown in Table S1, and conformations with the lowest docking scores are displayed in Table 1. The vina scores revealed strong interactions between the Amadori compounds/ carbohydrates and the target proteins. Additionally, the Amadori compounds had lower scores compared to those of the corresponding carbohydrates, which suggests that the former may be more closely associated with ALI than the latter. Detailed diagrams of the docking results of target proteins and ligands are shown in Figure S2.

\section{Discussion}

In the present study, a comprehensive network pharmacological method based on Amadori compounds, and a disease database search were used to identify the most useful molecular targets and mechanisms of the Amadori compounds associated with ALI and diabetes. As endogenous products of diabetes, Amadori compounds exhibit a 2-way regulation ability to influence the process of ALI via the activation of various protein receptors. Thus, it may be necessary to re-evaluate the relationships between ALI and diabetes. The Amadori compounds can be produced via the primary Maillard reaction of reduced carbohydrates (i.e., GLC and MAL) with amino acids due to the hyperglycemia in diabetics, which can also lead to an association between advanced glycation and diabetes complications (17). In addition, the mass spectrometric behaviors and fragmentation pathways of 2 Amadori compounds (i.e., GLC-TRP and MALTRP) were investigated by tandem MS in the positive and negative-ion mode, and 4 common precursor ions ([M$\mathrm{H}]^{-},[\mathrm{M}+\mathrm{H}]^{+},[\mathrm{M}+\mathrm{Na}]^{+}$and $\left.[\mathrm{M}+\mathrm{K}]^{+}\right)$were selected for the study of the fragmentation pathways. Because the charges of the precursor ions $\left([\mathrm{M}-\mathrm{H}]^{-}\right.$and $\left.[\mathrm{M}+\mathrm{H}]^{+}\right)$are located on the side of amino acids, the fragments of these ions can be mainly assigned to $\mathrm{X}$ ions because of the continuous crossring cleavages of sugar moieties. As for the cationization of alkali metal ions, the fragmentation mechanisms are relatively complex, especially for sodium adduction ions, which include $\mathrm{A}$ and $\mathrm{X}$ ions from sugar moieties' cross-ring cleavages, and the fragmentations of glycoside bonds and TRP terminus. The results obtained from these analyses illustrate that the charge states, the degree of delocalization, and the radius of adduct ions have a great effect on the fragmentation pathways of such precursor ions. These findings provide fundamental insights for further research on similar types of Amadori compounds (24). 
Comprehensive and user-friendly information on all annotated and predicted human genes is provided by GeneCards, which includes 1,451 genes related to ALI and integrates genomic, transcriptomic, proteomic, and clinical information related to these genes. We then used the Swiss TargetPrediction database and Cytoscape software to intersect the targets of the GLC-Amadori and MALAmadori compounds and obtain 'component-target-disease' mappings. GO and KEGG pathway enrichment analyses were subsequently conducted using $\mathrm{R}$ package to generate important findings via an integrated bioinformatical analysis. In terms of BPs, the targets of the GLC-Amadori and MAL-Amadori compounds were significantly enriched in blood pressure regulation, cellular responses to drugs, and vascular processes in the circulatory system. In terms of CC, both targets were significantly enriched in the membrane raft, membrane micro-domain, and membrane region. In terms of MF, both targets were enriched in the endopeptidase activity, amide binding, and peptide binding. The KEGG pathway analysis revealed that both targets were especially enriched in the PI3K-Akt signaling pathway, Rap1 signaling pathway, neuroactive ligand-receptor interaction, proteoglycans in cancer, and calcium signaling pathway.

The PPI target networks of GLC-Amadori and MALAmadori compounds were separately constructed via the STRING online database to support the discussion on the networks between the Amadori compounds and the target proteins associated with ALI. We comprehensively considered the top 10 targets of the 2 groups and selected VEGFA, CASP3, and SRC as hub targets of the Amadori compounds related to ALI. VEGFA plays a crucial role in the regulation of angiogenesis, vasculogenesis, and the epithelial cell (EC) growth factor, which is a key factor associated with increased lung vessel permeability in $\operatorname{ALI}(33,34)$. Given the importance of vascular integrity for lung function, significant correlations between VEGFA levels and respiratory failure have been observed (35). CASP3 is involved in the activation cascade of caspases responsible for apoptosis execution. Pulmonary EC apoptosis not only plays an important role in physiological processes during lung development, including vasculogenesis and angiogenesis, but also in the progression of ALI/ARDS (36). For example, findings on sepsis-induced ARDS in mice support the hypothesis that pulmonary microvascular EC death is a cause of barrier dysfunction and edema $(37,38)$. Moreover, inhibiting apoptosis by a broad-spectrum caspase inhibitor could prolong the survival of mice exposed to LPS (39). SRC can be activated following the engagement of different kinds of cell receptors, including immune response receptors, integrins, and other adhesion receptors; receptor protein-TYR kinases; G proteincoupled receptors, and cytokine receptors. The activation of RAB26-SRC signaling has been reported to provide a therapeutic opportunity for preventing vascular leakage in ALI, which means RAB26 exerts a protective effect of ALI on EC permeability, but this partly depends on the autophagic targeting of active SRC (40). Thus, SRC plays an important role in the regulation of pulmonary epithelial biology and responses to injury and inflammation. Furthermore, Amadori compounds also showed the moderate inhibitory activity of ACE $(41,42)$ and the stimulation of MMP2 secretion from cell $(43,44)$, which complexed the role of Amadori compounds as diabetes mediators in ALI/ARDS.

ALI is an inflammatory disease characterized by an unbalanced response with increased epithelial or endothelial damage; the pathologies of this syndrome include the destruction of alveolar-capillary membrane integrity, the excessive migration of neutrophils, and the promotion of inflammatory cytokines (45). The complex pathogenesis and lack of specific targeted drugs for ALI highlight the need for alternative treatments that could avoid previously identified risk factors and prevent disease progression $(46,47)$. In the present study, molecular docking studies were conducted to evaluate the binding orientation and affinity of small molecules to their targets; these properties were then used to compare binding energies and action sites based on protein structures. According to our molecular docking results, the Amadori compounds have potent effects on the homeostasis and pathogenesis of ALI, and have a greater affinity toward their hub targets than their corresponding carbohydrates. As Amadori compounds may have more contact sites for their target proteins than their corresponding carbohydrates, the former may have enhanced effects on ALI and diabetes (48). Further, ALI was observed to have differential effects following the activation of different targeted proteins; for example, VEGFA and CASP3 activation may promote ALI, while SRC activation may inhibit the progression of the disease. Our findings that Amadori compounds bi-directionally regulate ALI are consistent with those of previous reports (11-13). Due to the complex relationships between diabetes and ALI, the question of whether these compounds (as the medium of diabetes) are risk factors for ALI could not be determined 
through several signaling pathways in this work. Another Amadori compound (i.e., arginyl-fructosyl-GLC) has been reported to relieve cisplatin-induced acute kidney injury by regulating the NF- $\mathrm{\kappa B}$ and PI3K/Akt signaling pathways (49). Thus, our research not only extends current understandings of the risk factors associated with ALI but also provides a candidate compound library for the discovery of new active compounds related to the disease.

In conclusion, we analyzed the mass spectrometric behavior of typical Amadori compounds using tandem MS and identified the molecular mechanisms of such molecules in ALI via network pharmacology. We identified the potential targets and pathways responsible for the endogenous adjusting properties of Amadori compounds acting on ALI. We also identified 3 hub targets (i.e., VEGFA, CASP3, and SRC), and compared their binding energies to those of Amadori compounds and their corresponding carbohydrates using the molecular docking method. The underlying mechanisms of the Amadori compounds toward their targets require further characterization in vivo and in vitro; however, in silico predictions clearly show that the effects of these compounds on the bi-directional regulation of ALI are significantly enhanced following glycosylation. Our results should be explored further through more experiments.

\section{Acknowledgments}

We would like to thank Professor Shuying Liu, Changchun University of Chinese Medicine and Changchun Institute of Applied Chemistry Chinese Academy of Sciences, and Dr. Shuixing Wu, School of Chemistry and Chemical Engineering, Hainan Normal University, for their support in tandem mass spectrometry.

Funding: This work was supported by funding from the Maoming Science and Technology Program (Grant No. 2020KJZX003), the High-Level Hospital Construction Research Project of Maoming People's Hospital (Grant No. zx2020016), and the Doctoral Research Project of Maoming People's Hospital (Grant No. BS2020002).

\section{Footnote}

Reporting Checklist: The authors have completed the MDAR reporting checklist. Available at https://dx.doi. org/10.21037/apm-21-3298

Data Sharing Statement: Available at https://dx.doi. org/10.21037/apm-21-3298

Conflicts of Interest: All authors have completed the ICMJE uniform disclosure form (available at https://dx.doi. org/10.21037/apm-21-3298). All authors report this work was supported by funding from the Maoming Science and Technology Program (Grant No. 2020KJZX003), the HighLevel Hospital Construction Research Project of Maoming People's Hospital (Grant No. zx2020016), and the Doctoral Research Project of Maoming People's Hospital (Grant No. BS2020002). The authors have no other conflicts of interest to declare.

Ethical Statement: The authors are accountable for all aspects of the work in ensuring that questions related to the accuracy or integrity of any part of the work are appropriately investigated and resolved. The study was conducted in accordance with the Declaration of Helsinki (as revised in 2013).

Open Access Statement: This is an Open Access article distributed in accordance with the Creative Commons Attribution-NonCommercial-NoDerivs 4.0 International License (CC BY-NC-ND 4.0), which permits the noncommercial replication and distribution of the article with the strict proviso that no changes or edits are made and the original work is properly cited (including links to both the formal publication through the relevant DOI and the license). See: https://creativecommons.org/licenses/by-nc-nd/4.0/.

\section{References}

1. Diamond M, Peniston HL, Sanghavi D, et al. Acute respiratory distress syndrome. Treasure Island (FL): StatPearls Publishing; 2021.

2. Redant $\mathrm{S}$, Devriendt J, Botta I, et al. Diagnosing Acute Respiratory Distress Syndrome with the Berlin Definition: Which Technical Investigations Should be the Best to Confirm it? J Transl Int Med 2019;7:1-2.

3. Butt Y, Kurdowska A, Allen TC. Acute Lung Injury: A Clinical and Molecular Review. Arch Pathol Lab Med 2016;140:345-50.

4. Righetti RF, Dos Santos TM, Camargo LDN, et al. Protective Effects of Anti-IL17 on Acute Lung Injury Induced by LPS in Mice. Front Pharmacol 2018;9:1021.

5. Impellizzeri D, Bruschetta G, Esposito E, et al. Emerging drugs for acute lung injury. Expert Opin Emerg Drugs 2015;20:75-89. 
6. Rubenfeld GD, Herridge MS. Epidemiology and outcomes of acute lung injury. Chest 2007;131:554-62.

7. King H, Aubert RE, Herman WH. Global burden of diabetes, 1995-2025: prevalence, numerical estimates, and projections. Diabetes Care 1998;21:1414-31.

8. Kor DJ, Warner DO, Alsara A, et al. Derivation and diagnostic accuracy of the surgical lung injury prediction model. Anesthesiology 2011;115:117-28.

9. Gu WJ, Wan YD, Tie HT, et al. Risk of acute lung injury/ acute respiratory distress syndrome in critically ill adult patients with pre-existing diabetes: a meta-analysis. PLoS One 2014;9:e90426.

10. Yu S, Christiani DC, Thompson BT, et al. Role of diabetes in the development of acute respiratory distress syndrome. Crit Care Med 2013;41:2720-32.

11. Luo J, $\mathrm{Yu} \mathrm{H}, \mathrm{Hu} \mathrm{YH}$, et al. Early identification of patients at risk for acute respiratory distress syndrome among severe pneumonia: a retrospective cohort study. J Thorac Dis 2017;9:3979-95.

12. Yang P, Formanek P, Scaglione S, et al. Risk factors and outcomes of acute respiratory distress syndrome in critically ill patients with cirrhosis. Hepatol Res 2019;49:335-43.

13. Ji M, Chen M, Hong X, et al. The effect of diabetes on the risk and mortality of acute lung injury/acute respiratory distress syndrome: A meta-analysis. Medicine (Baltimore) 2019;98:e15095.

14. Vanhorebeek I, De Vos R, Mesotten D, et al. Protection of hepatocyte mitochondrial ultrastructure and function by strict blood glucose control with insulin in critically ill patients. Lancet 2005;365:53-9.

15. Chen HI, Yeh DY, Liou HL, et al. Insulin attenuates endotoxin-induced acute lung injury in conscious rats. Crit Care Med 2006;34:758-64.

16. Yaylayan VA, Huyghues-Despointes A. Chemistry of Amadori rearrangement products: analysis, synthesis, kinetics, reactions, and spectroscopic properties. Crit Rev Food Sci Nutr 1994;34:321-69.

17. Monnier VM, Sell DR, Dai Z, et al. The role of the amadori product in the complications of diabetes. Ann N Y Acad Sci 2008;1126:81-8.

18. Schalkwijk CG, Lieuw-a-Fa M, van Hinsbergh VW, et al. Pathophysiological role of Amadori-glycated proteins in diabetic microangiopathy. Semin Vasc Med 2002;2:191-7.

19. Mossine VV, Barnes CL, Mawhinney TP. Solubility and crystal structure of N-(1-deoxy-beta-D-fructopyranos1-yl)-1-histidine monohydrate ('D-fructose-1-histidine'). Carbohydr Res 2007;342:131-8.
20. Tarnawski M, Slepokura K, Lis T, et al. Crystal structure of N-(1-deoxy-beta-D-fructopyranos-1-yl)-L-proline-an Amadori compound. Carbohydr Res 2007;342:1264-70.

21. Davidek T, Kraehenbuehl K, Devaud S, et al. Analysis of Amadori compounds by high-performance cation exchange chromatography coupled to tandem mass spectrometry. Anal Chem 2005;77:140-7.

22. Hau J, Devaud S, Blank I. Detection of Amadori compounds by capillary electrophoresis coupled to tandem mass spectrometry. Electrophoresis 2004;25:2077-83.

23. Wang J, Lu YM, Liu BZ, et al. Electrospray positive ionization tandem mass spectrometry of Amadori compounds. J Mass Spectrom 2008;43:262-4.

24. Bai Y, Liang Y, Li G, et al. Metal-ion-assisted structural and anomeric analysis of Amadori compounds by electrospray ionization mass spectrometry. Rapid Commun Mass Spectrom 2021;35:e8960.

25. Berger SI, Iyengar R. Network analyses in systems pharmacology. Bioinformatics 2009;25:2466-72.

26. Gfeller D, Grosdidier A, Wirth M, et al. SwissTargetPrediction: a web server for target prediction of bioactive small molecules. Nucleic Acids Res 2014;42:W32-8.

27. Daina A, Michielin O, Zoete V. SwissTargetPrediction: updated data and new features for efficient prediction of protein targets of small molecules. Nucleic Acids Res 2019;47:W357-64.

28. Ashburner M, Ball CA, Blake JA, et al. Gene ontology: tool for the unification of biology. The Gene Ontology Consortium. Nat Genet 2000;25:25-9.

29. Kanehisa M, Goto S. KEGG: kyoto encyclopedia of genes and genomes. Nucleic Acids Res 2000;28:27-30.

30. Shannon P, Markiel A, Ozier O, et al. Cytoscape: a software environment for integrated models of biomolecular interaction networks. Genome Res 2003;13:2498-504.

31. Liu Y, Grimm M, Dai WT, et al. CB-Dock: a web server for cavity detection-guided protein-ligand blind docking. Acta Pharmacol Sin 2020;41:138-44.

32. Han L, Costello CE. Mass spectrometry of glycans. Biochemistry (Mosc) 2013;78:710-20.

33. Jesmin S, Zaedi S, Islam AM, et al. Time-dependent alterations of VEGF and its signaling molecules in acute lung injury in a rat model of sepsis. Inflammation 2012;35:484-500.

34. Epiphanio S, Campos MG, Pamplona A, et al. VEGF promotes malaria-associated acute lung injury in mice. PLoS Pathog 2010;6:e1000916. 
35. Thickett DR, Armstrong L, Christie SJ, et al. Vascular endothelial growth factor may contribute to increased vascular permeability in acute respiratory distress syndrome. Am J Respir Crit Care Med 2001;164:1601-5.

36. Chambers E, Rounds S, Lu Q. Pulmonary Endothelial Cell Apoptosis in Emphysema and Acute Lung Injury. Adv Anat Embryol Cell Biol 2018;228:63-86.

37. Gill SE, Taneja R, Rohan M, et al. Pulmonary microvascular albumin leak is associated with endothelial cell death in murine sepsis-induced lung injury in vivo. PLoS One 2014;9:e88501.

38. Gill SE, Rohan M, Mehta S. Role of pulmonary microvascular endothelial cell apoptosis in murine sepsisinduced lung injury in vivo. Respir Res 2015;16:109.

39. Kawasaki M, Kuwano K, Hagimoto N, et al. Protection from lethal apoptosis in lipopolysaccharide-induced acute lung injury in mice by a caspase inhibitor. Am J Pathol 2000;157:597-603.

40. Dong W, He B, Qian H, et al. RAB26-dependent autophagy protects adherens junctional integrity in acute lung injury. Autophagy 2018;14:1677-92.

41. Harohally NV, Srinivas SM, Umesh S. ZnCl2-mediated practical protocol for the synthesis of Amadori ketoses. Food Chem 2014;158:340-4.

42. Srinivas SM, Harohally NV. Improved synthesis of lysineand arginine-derived Amadori and Heyns products and in vitro measurement of their angiotensin I-converting enzyme inhibitory activity. J Agric Food Chem

Cite this article as: Bai Y, Li J, Wang G, Liang G, He Y, $\mathrm{Hu}$ L, Chen C. Mass spectrometric behaviors and molecular mechanisms of Amadori compounds between acute lung injury and diabetes based on network pharmacology. Ann Palliat Med 2021;10(12):12441-12455. doi: 10.21037/apm-21-3298
2012;60:1522-7.

43. Oak JH, Nakagawa K, Oikawa S, Miyazawa T. Amadoriglycated phosphatidylethanolamine induces angiogenic differentiations in cultured human umbilical vein endothelial cells. FEBS Lett 2003;555:419-23.

44. Nakagawa K, Oak JH, Miyazawa T. Angiogenic potency of Amadori-glycated phosphatidylethanolamine. Ann N Y Acad Sci. 2005;1043: 413-6.

45. Ji Y, Gao F, Sun B, et al. Angiotensin-Converting Enzyme 2 Inhibits Apoptosis of Pulmonary Endothelial Cells During Acute Lung Injury Through Suppressing SMAD2 Phosphorylation. Cell Physiol Biochem 2015;35:2203-12.

46. Mowery NT, Terzian WTH, Nelson AC. Acute lung injury. Curr Probl Surg 2020;57:100777.

47. Kuldanek SA, Kelher M, Silliman CC. Risk factors, management and prevention of transfusion-related acute lung injury: a comprehensive update. Expert Rev Hematol 2019;12:773-85.

48. Arif B, Ashraf JM, Moinuddin, et al. Structural and immunological characterization of Amadori-rich human serum albumin: role in diabetes mellitus. Arch Biochem Biophys 2012;522:17-25.

49. Li RY, Zhang WZ, Yan XT, et al. Arginyl-fructosylglucose, a Major Maillard Reaction Product of Red Ginseng, Attenuates Cisplatin-Induced Acute Kidney Injury by Regulating Nuclear Factor $\kappa \mathrm{B}$ and Phosphatidylinositol 3-Kinase/Protein Kinase B Signaling Pathways. J Agric Food Chem 2019;67:5754-63. 
A

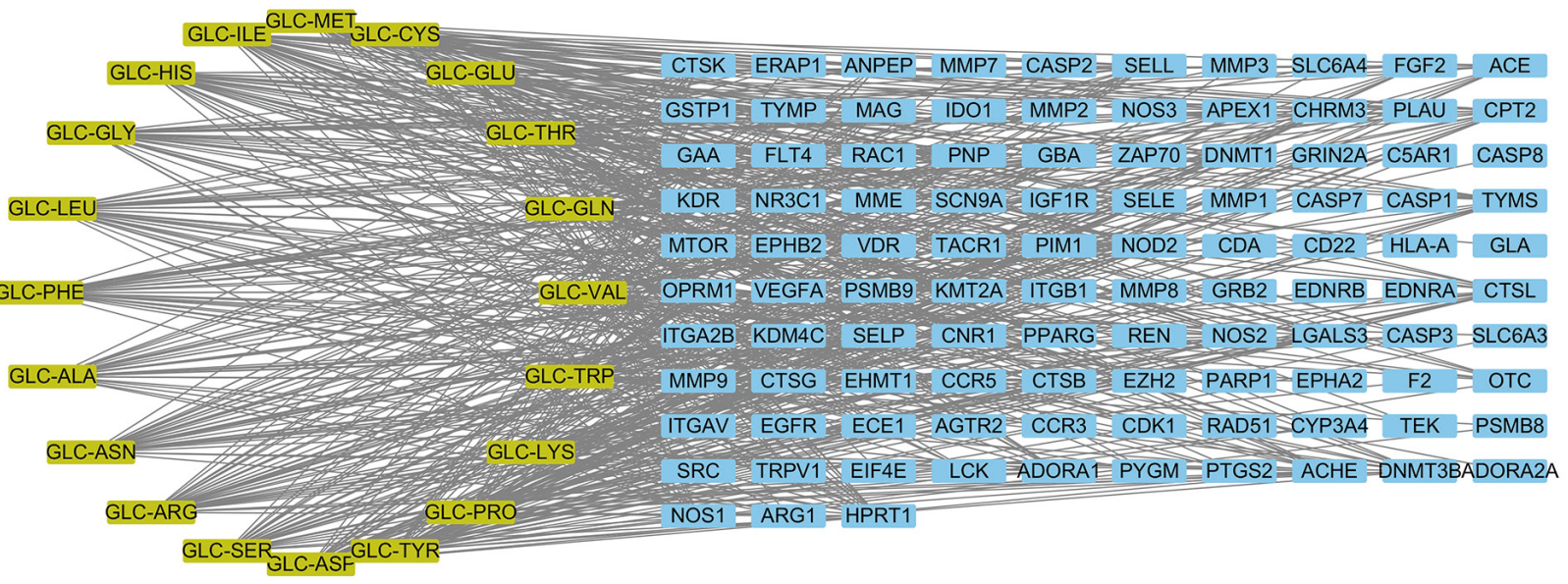

B

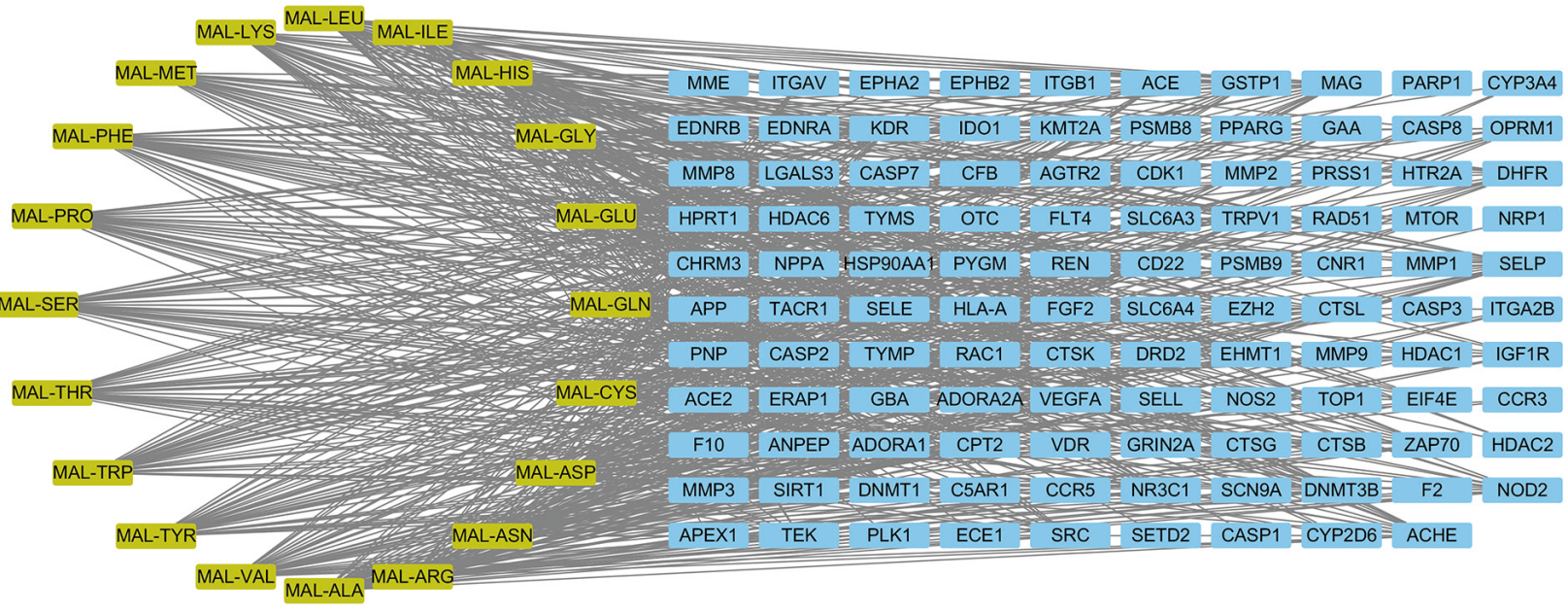

Figure S1 Compound-disease regulatory networks showing the targeted relationship between the Amadori compounds and the intersection genes. (A) Glucose-Amadori compounds; (B) Maltose-Amadori compounds. 
Table S1 First 5 vina scores and cavity information of the docking simulation pose for Amadori compounds/carbohydrates and targeted proteins

\begin{tabular}{|c|c|c|c|c|c|c|c|c|c|c|c|c|c|c|c|c|c|c|c|c|c|c|c|c|c|c|c|c|c|c|c|c|}
\hline \multirow{3}{*}{ Target ID } & \multicolumn{8}{|c|}{ Glucose } & \multicolumn{8}{|c|}{ GLC-TRP } & \multicolumn{8}{|c|}{ maltose } & \multicolumn{8}{|c|}{ MAL-TRP } \\
\hline & \multirow{2}{*}{$\begin{array}{l}\text { Vina } \\
\text { score }\end{array}$} & \multirow{2}{*}{$\begin{array}{c}\text { Cavity } \\
\text { size }\end{array}$} & \multicolumn{3}{|c|}{ Center } & \multicolumn{3}{|c|}{ Size } & \multirow{2}{*}{$\begin{array}{l}\text { Vina } \\
\text { score }\end{array}$} & \multirow{2}{*}{$\frac{\text { Cavity }}{\text { size }}$} & \multicolumn{3}{|c|}{ Center } & \multicolumn{3}{|c|}{ Size } & \multirow{2}{*}{$\begin{array}{l}\text { Vina } \\
\text { score }\end{array}$} & \multirow{2}{*}{$\frac{\text { Cavity }}{\text { size }}$} & \multicolumn{3}{|c|}{ Center } & \multicolumn{3}{|c|}{ Size } & \multirow{2}{*}{$\begin{array}{l}\text { Vina } \\
\text { score }\end{array}$} & \multirow{2}{*}{$\frac{\text { Cavity }}{\text { size }}$} & \multicolumn{3}{|c|}{ Center } & \multicolumn{3}{|c|}{ Size } \\
\hline & & & $\mathrm{x}$ & $\mathrm{y}$ & $z$ & $\mathrm{x}$ & y & $z$ & & & $\mathrm{x}$ & y & $z$ & $\mathrm{x}$ & $\mathrm{y}$ & $z$ & & & $x$ & $y$ & $z$ & $\mathrm{x}$ & $\mathrm{y}$ & $z$ & & & $\mathrm{x}$ & $\mathrm{y}$ & $z$ & $\mathrm{x}$ & $\mathrm{y}$ & $z$ \\
\hline \multirow[t]{5}{*}{ VEGFA (PDB:4KZN) } & -4.5 & 43 & -14 & 1 & 3 & 16 & 16 & 16 & -5.9 & 25 & 7 & -2 & 16 & 24 & 24 & 24 & -4.9 & 43 & -14 & 1 & 3 & 20 & 20 & 20 & -6.1 & 25 & 7 & -2 & 16 & 27 & 27 & 27 \\
\hline & -4.1 & 25 & 7 & -2 & 16 & 16 & 16 & 16 & -5.8 & 43 & -14 & 1 & 3 & 24 & 24 & 24 & -4.7 & 25 & 7 & -2 & 16 & 20 & 20 & 20 & -6 & 43 & -14 & 1 & 3 & 27 & 27 & 27 \\
\hline & -3.9 & 39 & 28 & -2 & 14 & 16 & 16 & 16 & -5.8 & 22 & 22 & 5 & 10 & 24 & 24 & 24 & -4.3 & 46 & 18 & -1 & 16 & 20 & 20 & 20 & -5.9 & 46 & 18 & -1 & 16 & 27 & 27 & 27 \\
\hline & -3.9 & 22 & 22 & 5 & 10 & 16 & 16 & 16 & -5.7 & 46 & 18 & -1 & 16 & 24 & 24 & 24 & -4 & 39 & 28 & -2 & 14 & 20 & 20 & 20 & -5.4 & 39 & 28 & -2 & 14 & 27 & 27 & 27 \\
\hline & -3.4 & 46 & 18 & -1 & 16 & 16 & 16 & 16 & -4.9 & 39 & 28 & -2 & 14 & 24 & 24 & 24 & -4 & 22 & 22 & 5 & 10 & 20 & 20 & 20 & -5.4 & 22 & 22 & 5 & 10 & 27 & 27 & 27 \\
\hline \multirow[t]{4}{*}{ CASP3 (PDB:1 QX3) } & -4.5 & 266 & -3 & 31 & 14 & 16 & 16 & 16 & -7.2 & 266 & -3 & 31 & 14 & 24 & 24 & 24 & -5.8 & 266 & -3 & 31 & 14 & 20 & 20 & 20 & -7.7 & 266 & -3 & 31 & 14 & 27 & 27 & 27 \\
\hline & -4.2 & 696 & 13 & 35 & -13 & 16 & 16 & 16 & -6.5 & 696 & 13 & 35 & -13 & 24 & 24 & 24 & -5 & 389 & 7 & 47 & 10 & 20 & 20 & 20 & -6.6 & 86 & 21 & 45 & 9 & 27 & 27 & 27 \\
\hline & -4.2 & 139 & 16 & 52 & -6 & 16 & 16 & 16 & -5.8 & 139 & 16 & 52 & -6 & 24 & 24 & 24 & -5 & 86 & 21 & 45 & 9 & 20 & 20 & 20 & -6.4 & 139 & 16 & 52 & -6 & 27 & 27 & 27 \\
\hline & -3.7 & 389 & 7 & 47 & 10 & 16 & 16 & 16 & -5.3 & 389 & 7 & 47 & 10 & 24 & 24 & 24 & -4.7 & 139 & 16 & 52 & -6 & 20 & 20 & 20 & -5.7 & 389 & 7 & 47 & 10 & 27 & 27 & 27 \\
\hline \multirow[t]{5}{*}{ SRC (PDB:2SRC) } & -5.6 & 877 & 18 & 27 & 58 & 16 & 16 & 16 & -8.2 & 405 & 11 & 19 & 59 & 24 & 24 & 24 & -7 & 405 & 11 & 19 & 59 & 20 & 20 & 20 & -9.5 & 877 & 18 & 27 & 58 & 27 & 27 & 27 \\
\hline & -5.5 & 676 & 27 & 45 & 80 & 16 & 28 & 24 & -8.1 & 877 & 18 & 27 & 58 & 24 & 24 & 24 & -6.7 & 877 & 18 & 27 & 58 & 20 & 20 & 20 & -9.2 & 405 & 11 & 19 & 59 & 27 & 27 & 27 \\
\hline & -5.4 & 709 & 34 & 45 & 63 & 16 & 16 & 16 & -8 & 709 & 34 & 45 & 63 & 24 & 24 & 24 & -6.6 & 676 & 27 & 45 & 80 & 20 & 28 & 20 & -8.4 & 709 & 34 & 45 & 63 & 27 & 27 & 27 \\
\hline & -5.3 & 405 & 11 & 19 & 59 & 16 & 16 & 16 & -8 & 676 & 27 & 45 & 80 & 24 & 24 & 24 & -6.4 & 709 & 34 & 45 & 63 & 20 & 20 & 20 & -8.1 & 676 & 27 & 45 & 80 & 27 & 27 & 27 \\
\hline & -5.2 & 413 & 19 & 42 & 56 & 16 & 16 & 22 & -7.2 & 413 & 19 & 42 & 56 & 24 & 24 & 24 & -6.4 & 413 & 19 & 42 & 56 & 20 & 20 & 20 & -8.1 & 413 & 19 & 42 & 56 & 27 & 27 & 27 \\
\hline
\end{tabular}




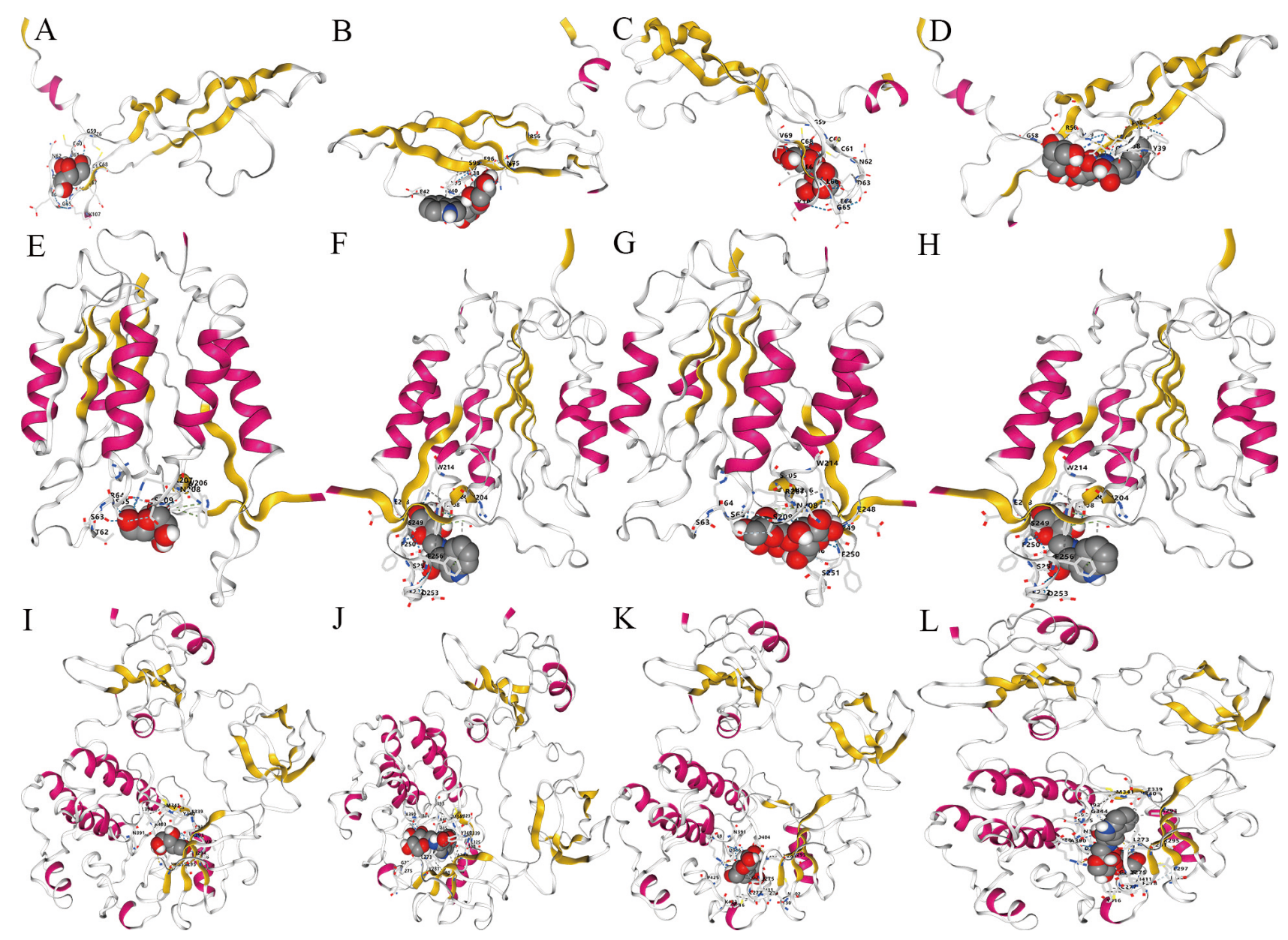

Figure S2 Schematic diagram of molecular docking. (A) Vascular endothelial growth factor A-Glucose; (B) Vascular endothelial growth factor A-Glucose-Tryptophan; (C) Vascular endothelial growth factor A-Maltose; (D) Vascular endothelial growth factor A-MaltoseTryptophan; (E) Caspase-3-Glucose; (F) Caspase-3-Glucose-Tryptophan; (G) Caspase-3-Maltose; (H) Caspase-3-Maltose-Tryptophan; (I) Proto-oncogene tyrosine-protein kinase Src-Glucose; (J) Proto-oncogene tyrosine-protein kinase Src-Glucose-Tryptophan; (K) Protooncogene tyrosine-protein kinase Src-Maltose; (L) Proto-oncogene tyrosine-protein kinase Src - Maltose-Tryptophan. 